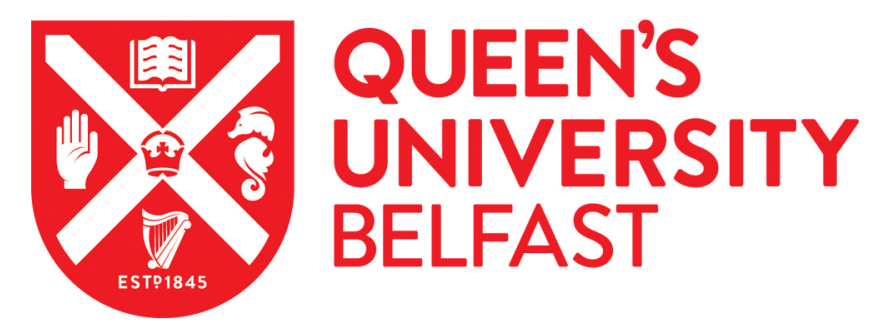

\title{
Allowing imprisoned fathers to parent: maximising the potential benefits of prison based parenting programmes
}

Hayes, D., Butler, M., Devaney, J., \& Percy, A. (2018). Allowing imprisoned fathers to parent: maximising the potential benefits of prison based parenting programmes. Child Care in Practice, 24(2), 181-197. https://doi.org/10.1080/13575279.2017.1420038

Published in:

Child Care in Practice

Document Version:

Peer reviewed version

Queen's University Belfast - Research Portal:

Link to publication record in Queen's University Belfast Research Portal

Publisher rights

(C) 2017 The Child Care in Practice Group.

This work is made available online in accordance with the publisher's policies. Please refer to any applicable terms of use of the publisher.

\section{General rights}

Copyright for the publications made accessible via the Queen's University Belfast Research Portal is retained by the author(s) and / or other copyright owners and it is a condition of accessing these publications that users recognise and abide by the legal requirements associated with these rights.

Take down policy

The Research Portal is Queen's institutional repository that provides access to Queen's research output. Every effort has been made to ensure that content in the Research Portal does not infringe any person's rights, or applicable UK laws. If you discover content in the Research Portal that you believe breaches copyright or violates any law, please contact openaccess@qub.ac.uk. 


\section{Allowing imprisoned fathers to parent: maximising the potential benefits of prison based parenting programmes}

Dr Michelle Butler

School of Social Sciences, Education \& Social Work, Queen's University Belfast, Belfast, United Kingdom

Dr David Hayes

School of Social Sciences, Education \& Social Work, Queen's University Belfast, Belfast, United Kingdom

Dr John Devaney

School of Social Sciences, Education \& Social Work, Queen's University Belfast, Belfast, United Kingdom

Dr Andrew Percy

School of Social Sciences, Education \& Social Work, Queen's University Belfast, Belfast, United Kingdom

The corresponding author is $\mathrm{Dr}$ Michelle Butler:

Address: $\quad 6$ College Park,

Belfast,

BT7 1LP

United Kingdom

Email: $\quad$ michelle.butler@qub.ac.uk

Telephone: 00442890973956 
Word count: 6920 (excluding references -8160 including references)

Dr Michelle Butler is a lecturer in criminology at Queen's University Belfast. She specializes in prison research, parental imprisonment, criminological psychology, restorative justice and penal reform. (ORCID: 0000-0002-6983-6215) (Twitter: @MichelleBQUB)

Dr David Hayes is a senior lecturer in social work at Queen's University Belfast. He specializes in childhood adversity, child wellbeing, child protection and children's experiences of the criminal justice system (ORCID: 0000-0001-7053-9069)

Dr John Devaney is a senior lecturer in social work at Queen's University Belfast. He specializes in child abuse and neglect, family relationships, impact of childhood adversity across the lifespan and developing child welfare policy (ORCID: 0000-0001-8300-8339) (Twitter: @Jdev65)

Dr Andrew Percy is a senior lecturer in criminology at Queen's University Belfast. He specializes in the alcohol and drug use of young people, research design and measurement as well as evaluative research. 


\begin{abstract}
During imprisonment, fathers are separated from their families and contact is limited. When delivering a prison based parenting programme, providing an opportunity to rehearse newly acquired parenting skills can be key for mastering the performance of these skills and using these skills to improve father-child relationships. This paper takes an in-depth look at how one parenting programme in Northern Ireland sought to overcome this challenge by providing additional opportunities to parent via increased telephone contact and special family friendly visits. Using a combination of in-depth interviews and observations, how fathers and their families responded to this increased contact is explored, as well as the extent to which this increased contact facilitated the acquisition of the parenting skills being taught on the programme. It is argued that while prison based parenting programmes can improve parenting skills and father-child relationships, their potential long-term effectiveness may be limited by wider prison policies, procedures and practices surrounding prison visitation, telephone access and the progression of fathers following the completion of such programmes. Recommendations and suggestions for future practice are offered.
\end{abstract}

Keywords: Parenting, services, behaviour, parental imprisonment, prison based parenting programmes. 
Nowadays, imprisonment is generally used to punish wrongdoing by depriving an individual of their liberty and separating them from loved ones (Garland, 1990). However, the potential for this separation to negatively affect the development and wellbeing of children has become increasingly documented in countries such as the USA, UK, Australia, New Zealand and Denmark (Flynn \& Eriksson, 2015; Foster \& Hagan, 2009; Hagan \& Foster, 2012; Wildeman, 2009). While the majority of research on parental imprisonment has focused on mothers, there is a growing recognition of the need to look at the impact of fathers' imprisonment, as the majority of those imprisoned internationally are men (Walmsley, 2016). For those with positive father-child relationships, this separation can weaken and disrupt father-child interactions and increase adverse outcomes for children (Dennison, Smallbone, \& Occhipinti, 2017; Sharratt, 2014). Examples of such adverse outcomes that have been identified in research conducted in the USA and the UK include reduced wellbeing, poorer educational attainment, criminality, social exclusion, mental health problems and behavioural difficulties (Foster \& Hagan, 2009; Hagan \& Dinovitzer, 1999; Murray \& Murray, 2010; Wakefield \& Wildeman, 2011; Wildeman, 2014). Prison based parenting programmes in the USA, the UK and Australia have sought to mitigate the negative effects of separation by increasing family contact and improving parenting skills (Hoffmann, Byrd, \& Kightlinger, 2010; Meek, 2007; Newman, Fowler, \& Cashin, 2011). Yet, one of the challenges faced by such programmes is how prison policies, procedures and practices (for example, the lack of access to toys or games during standard prison visits) can curtail opportunities to rehearse parenting skills, as well as the amount and quality of contact fathers have with their children (Dennison et al., 2017; Hutton, 2016; Sharratt, 2014).

This paper takes an in-depth look at how one prison based parenting programme in Northern Ireland sought to overcome these difficulties by providing additional opportunities for contact between imprisoned fathers and their children. Responses to this increased contact are examined to explore if it helped improve father-child relationships and the acquisition of parenting skills. It is argued that while prison based parenting programmes can enhance parenting skills and 
contribute to improvements in father-child relationships, this is dependent on the extent fathers are allowed to use these skills while imprisoned to improve relationships with their children.

\section{Prison based parenting programmes}

There are a range of parenting programmes offered in prison (Buston, Parkes, Thomson, Wight, \& Fenton, 2012; Hoffmann et al., 2010; Loper \& Tuerk, 2006; Newman et al., 2011). These programmes vary in their format but usually incorporate parenting classes, child friendly visiting arrangements, increased family contact and support for family members (Barnardo's, 2015; Barr et al., 2011; Barr et al., 2014; Boswell, Poland, \& Price, 2010; Buston et al., 2012; Meek, 2007; Purvis, 2013). Research in the USA, UK and Australia indicates that these programmes are largely beneficial, at least in the short-term, resulting in increased parenting skills, confidence and ability to understand children's needs, as well as improved family communication and relationships (Boswell et al., 2010; Buston et al., 2012; Loper \& Tuerk, 2006; McCrudden, Braiden, McCormack, Sloan, \& Treacy, 2014; Purvis, 2013). Nevertheless, the fundamental challenge for these programmes is the separation of imprisoned fathers from their children and how fathers can maintain contact with their children while imprisoned (Buston et al., 2012; Loper \& Tuerk, 2006; Purvis, 2013).

Both US and European research indicates that telephone calls, letters and visits are the most common ways in which imprisoned parents maintain contact with their children (La Vigne, Naser, Brooks, \& Castro, 2005; Sharratt, 2014). Yet, prisons in different jurisdictions and at different security levels vary in the policies, practices and procedures they use to govern visitation, telephone access and letter-writing (Hutton, 2016; La Vigne et al., 2005; Sharratt, 2014). These differences partially explain why the effect of parental imprisonment on child adverse outcomes can vary between jurisdictions, with some jurisdictions experiencing worse outcomes (e.g. the UK) than others (e.g. the Netherlands or Sweden) (Besemer, van der Geest, Murray, Bijleveld, \& Farrington, 2011; Hutton, 2016; Murray, Janson, \& Farrington, 2007). For example, crowded prison visiting areas and restrictions on movement and physical contact can create an artificial environment for father- 
child interactions, resulting in strained communications and poor quality interactions (Dennison et al., 2017; Hutton, 2016; Sharratt, 2014). Over time, this type of contact can weaken social bonds and contribute to relationship breakdown (Dennison et al., 2017). For this reason, prisons which adopt child friendly visiting arrangements are believed to be more effective at protecting children's wellbeing and building positive father-child relationships (Dennison et al., 2017; Poehlmann, Dallaire, Loper, \& Shear, 2010). Moreover, maintaining contact is not only important for children but it also provides fathers with an opportunity to rehearse their parenting skills and reaffirm their identity as a parent (Dennison et al., 2017).

Skill acquisition is considered an important component of many skills based programmes and is generally understood as a three-stage process involving: (1) acquiring new knowledge; (2) consolidating knowledge through practice; and (3) automating the performance of new skills through frequent use and rehearsal (Proctor \& Dutta, 1995). Infrequent use of new skills can lead to a failure to accurately perform and retain skills, increasing the likelihood of new skills being lost and forgotten (Kim, Ritter, \& Koubek, 2013; Proctor \& Dutta, 1995). Within parenting programmes, encouraging parents to practice newly acquired skills has been found to improve skill retention, performance and child outcomes (Bronte-Tinkew et al., 2008; Stokes et al., 2016). Given the separation imprisoned parents experience from their children, opportunities to practice newly acquired parenting skills may be essential, if these skills are to be successfully retained and mastered. In this study, how one Northern Ireland prison based parenting programme at Maghaberry Prison, the Families Matter programme, sought to overcome these difficulties is explored.

\section{The present paper}

The political conflict in Northern Ireland has played a considerable role in shaping the Northern Ireland prison system with the challenges posed by political prisoners, protests, hunger strikes and violence, historically contributing to a more restrictive, security focused regime, especially within 
Maghaberry Prison (Butler, 2016). While recent reforms have sought to transform the prison service, Maghaberry prison remains the highest security category prison in Northern Ireland and political prisoners continue to be held there (Butler, 2016). The findings presented in this paper are drawn from a project investigating the design, rationale and implementation of the Families Matter programme, as well as how fathers, families and staff responded to the programme (see Butler, Hayes, Devaney \& Percy, 2015). This project examined the strengths and weaknesses of the programme design, its implementation and its ability to reduce some of the negative effects associated with parental imprisonment (see Butler et al., 2015). This paper draws on these findings to provide an in-depth exploration of the level of family contact participants experienced prior to and during the programme and how this contact affected family relationships and parenting skill acquisition. At the time of the research, the Families Matter programme was an adult male seventeen-week residential parenting programme based at Maghaberry Prison, Northern Ireland. This programme was jointly developed by Barnardo's Northern Ireland and the Northern Ireland Prison Service and opened to fathers on remand and sentenced to long and short periods of custody (see Butler et al., 2015 for further information about the programme). Assessments were also conducted with fathers to assess their parenting skills and quality of parental relationships before joining the programme. The programme sought to improve father-child relationships by increasing the frequency and quality of father-child contact and strengthen parenting skills via participation in parenting classes and a range of other educational and family focused activities. The frequency and quality of family contact was increased by providing fathers with extra telephone access and special monthly family friendly visits, in addition to the normal prison visits that were available. Fathers and their families were only allowed to avail of these additional opportunities for contact during the programme and returned to pre-programme levels of contact upon programme completion. This paper focuses specifically on how the additional opportunities for contact were responded to by fathers and their families to explore if it helped improve relationships and the acquisition of parenting skills. 


\section{Methods}

\section{$\underline{\text { Research design }}$}

A mixed methods approach combining observations and interviews was used to examine the design, rationale, implementation and effect of programme participant. Ten days of non-participant observation was conducted to observe programme content and delivery, as well as how fathers and their families responded to the programme. Observations were deemed an essential component of the methodology as the 'what works' literature indicates that how programmes are designed and delivered can influence their effectiveness (Andrews \& Dowden, 2005; Hollin, 1995; Lipsey, 1995). Indepth semi-structured interviews were conducted with 42 individuals, consisting of 18 fathers, 7 family members and 17 staff (please contact the authors for a copy of the interview schedules used). All bar one of the fathers agreed to participate in the study. Fathers were interviewed twice (halfway through the programme and on completion) to investigate if responses changed over time. Observations were also ongoing during this time, allowing interview responses to be compared with observed behaviour. Family members and staff were interviewed once on programme completion.

\section{Procedure}

Ethical approval was obtained from three ethics committees; Queen's University Belfast, the Northern Ireland Prison Service and Barnardo's UK. Full security clearance was obtained for the research team, and relevant professional guidelines and protocols were followed.

Potential participants were identified and recruited through their involvement in the Families Matter programme and were informed of the study using a combination of verbal announcements, information sessions, posters and information sheets. The voluntary nature of the research was 
stressed and potential participants were advised that they could refuse to answer questions or withdraw from the study at any stage, without any negative consequences. In addition, the limits to confidentiality and anonymity were outlined and all were aware that disclosures of abuse, staff malpractice, harm to self/others and attempts to escape would be reported to a relevant authority. Due to the small number of people participating in the programme, potentially identifying information has been removed in an attempt to protect participants' confidentiality and anonymity.

\section{Data analysis}

A theory of action approach was used to analyse and interpret the observations. This involves attempting to make links between events occurring on the programme and their actual and potential effect on individuals (Friedman \& Antal, 2005; Parson, Shils, \& Smelser, 2001). The interview data were analysed using NVivo and interpreted using thematic analysis. Thematic analysis is a qualitative methodology used to identify, analyse and report patterns or themes in qualitative data (Braun \& Clarke, 2006). This method of analysis was used to identify recurring themes in the participants' perceptions and experiences of family contact, as well as how family contact may affect family relationships and the acquisition of parenting skills. Quotes from the interviews with fathers, family members and staff that have been chosen for inclusion in the findings section as they exemplify the themes being discussed. Data triangulation was used to crosscheck the findings emerging from the interviews with those from the observations, to ensure that the claims, conclusions and recommendations drawn from the research were accurate and supported by the data (Bryman, 2008).

\section{Findings}

The findings are divided into two sections. The first section compares experiences of contact before and during the programme to examine if this increased contact helped improve father-child 
relationships. The second section explores whether these additional opportunities for contact facilitated the acquisition of the parenting skills fathers were being taught while on the programme.

\section{Families' experiences of contact before and during the programme}

Regardless of whether the father had been on remand or sentenced, families reported a noticeable difference in the amount and quality of contact they experienced once they joined the Families Matter programme. Prior to taking part in the programme, limited telephone contact was reported. Staff shortages had resulted in an unpredictable prison regime, with fathers' access to telephones frequently being curtailed with little advance warning. This meant that fathers were unable to contact their families as expected, frequently leaving children and partners feeling angry, annoyed, fearful, hurt and/or worried about their fathers. This was believed to damage children's wellbeing (as well as the wellbeing of fathers and partners) and to contribute to a more negative communicative patterns within the family. It also meant that conversations were often cut short due to the number of people seeking to use the telephone in a short amount of time:

"You get to use the phone at night for five minutes and you are locked back up again, so your mental state isn't good at all. [...] Then when you phone the wife [...] you would be in a bad mood. [...] It is not good for the kids. [...] When they don't get that [phone call] it makes them sad. And then it makes you sad. [...] It is a vicious circle." (Participant 9 - Father) Concerns were also expressed about the normal prison visits. Some family members reported feeling judged while attending these visits, damping their desire to continue visitation and contributing to negative feelings towards fathers/partners for exposing them to these situations:

"The [normal prison] visits [...] were stressful, very short, very upsetting. [...] Just feeling judged as a parent with a new child going into a prison. [...] Sometimes I would have felt angry like, because of what you are going through [...] and a bit frustrated maybe, with [father]." (Participant 42 - Family member) 
Fathers and family members described how prison security protocols, designed to prevent the passing of contraband, restricted the ability of fathers to move and interact with their children, inhibiting natural father-child interactions:

"The wee $2 \mathrm{yr}$ old was not going to sit on a seat for an hour. She gets up and starts wanting to toddle away. And if I stand up I get told to sit down. So I can't really play with her. [...] If I have to fix her wee skirt [...] straight away there is an officer standing behind me [...] they think I am trying to get something out of her clothes, or something." (Participant 8 - Father) Parents were also worried about children witnessing aggressive incidents and/or being accidentally harmed by prison staff as they sought to intervene to prevent the smuggling of contraband or inappropriate behaviour during normal prison visits:

"On the normal visit [...] they [another couple] were fighting in the middle of the visit and [...] he had punched a woman in the face and [...] luckily enough it was the two wee ones [children], and we were able to keep their heads away and they didn't really notice what was going on. Like if it had been the two bigger ones [children] [...] it would have been terrible. They wouldn't have went back in [to the prison]." (Participant 36 - Family member) "It just worries you that something is going to kick off [...] and before you know it the prison officers are in and [...] they don't think of a child [...] seeing this and what it may do to them. They are only there to solve a problem." (Participant 4 - Father) While fathers and partners understood the need for prison staff to act quickly to intervene in situations, they were worried about the potential impact witnessing these events may have on their children:

“Them [normal prison] visits [...] there's been a few people jumped on [...] who were bringing in contraband. [...] It had a big impact on the kids. My wee girl started crying, thinking that that was the way I was being treated. And the missus too." (Participant 9 Father) 
"We have seen stuff that I would never have wanted them [children] to see, but what do you do?" (Participant 37 - Family member)

The amount of people attending the normal prison visits also meant that these were often very noisy. This was perceived as adding to the stressful nature of the visit, as well as being challenging for children with autism or other development disorders:

“It was that loud [...] you couldn't hear yourself think, let alone hear what you were saying. So we argued quite a bit. [...] He [father] couldn't hear me and then I was getting frustrated. [...] It's stressful." (Participant 41 - Family member)

“My son can't handle noise, so when he comes up and visits, he [...] is basically punishing himself [...] because he does suffer from ADHD in a way that noise really does affect his way of thinking. And I can see him putting his hands over his ears, and it hurts me to watch him. But he doesn't want to miss the visit so he puts himself through this." (Participant 12 Father)

In some cases, fathers explained that they had to coax their children to attend the normal prison visits due to their child's dislike of the noise:

"She has said to me a few times “Daddy I don't want to go to them wee [normal] visits again because they are too noisy". But I end up coaxing her and saying "I have loads of sweeties love, for you"." (Participant 17 - Father)

In contrast, the family friendly visits provided by Families Matter programme were viewed as being less stressful and offering a more normalised environment for father-child interactions:

"I think it is a bit of normality for the kids [...] as normal as it can be. [...] They just really loved it. Getting to eat lunch together, just having [father] able to play with them and talk to them and if one of them needed one on one attention he [father] was able to do that and [...] it was excellent" (Participant 36 - Family member) The family visits differed substantially from the normal prison visits, both in their duration (four hours compared to one hour) and in how fathers were able to interact with their children. Unlike 
the normal prison visits, fathers were not restricted in their movements so they could play, run, walk and eat with their children. Prison staff overseeing the special family visits were also mindful of how their actions could be interpreted by children and, while security concerns remained important, they were balanced with the needs of children and families:

"He [father] can get up and interact with them [children]. [...] That was the main difference.

$[\ldots]$ It is a whole lot more relaxed. Yes, you are being watched but you are [...] not feeling as if you were stepping out of line if you move one way or [...] another way." (Participant 36 Family member)

The less stressful nature of these family visits was perceived as being particularly beneficial for children:

"The family visits were, yeah. I would rather have them than the other [normal] visits. [...] It was more relaxing and we looked forward to that one instead of the normal one. [...] It was better for the children and it was a lot less stressful for everyone." (Participant 41 - Family members)

As such, the family visits were viewed as providing more quality father-child contact, providing fathers with an opportunity to rebuild/strengthen relationships with their children:

"It has just built that bond back, because he [father] was losing it with [child]. [...] Whenever he went inside [to prison] [...] it was like [child] thought [father] had just left him. [...] He hated [father] and resented him. So [...] with the [family] visits they regained it again." (Participant 41 - Family member)

The Families Matter programme also sought to increase family contact by providing extra telephone access to fathers at times which were convenient for families. The residential nature of the programme facilitated this increased telephone access and through speaking with their children on the telephone, it was argued that fathers could continue to parent their children from prison. Fathers and families believed this telephone contact was a very important mechanism by which fathers could maintain contact with their children in between visits: 
"You can just jump on the phone whenever you feel like it. [...] It definitely is [very important] like." (Participant 10 - Father)

Families responded very positively to the additional opportunities for family contact provided by the Families Matter programme. Accounts of children becoming happier, acting out less, relationships improving and fathers becoming more attuned to the needs of children were frequently heard:

"It did improve [relationships with children] because [...] they [children] were happier. It lifted their wee spirits [...] it was like, just like they had him [back] again." (Participant 40 Family member)

"Yes, we are a lot more happy. A lot more positive. [...] [Without the Families Matter programme] maybe we wouldn't be together. Wouldn't be as close. Because them one hour [normal] visits are horrendous. [...] We could have drifted. [...] Because they [normal visits] are so stressful, the one hour visits, you sort of think, you know, you go down there, by the time you get in there, the noise, he [father] is not allowed off the seat, he can't bond with the child, all the stress. [...] You know, I mightn't have went up every week. The family visit like nearly made you go up." (Participant 40 - Family member)

However, while these family visits provided a less stressful environment for family interactions and helped to prevent family relationships deteriorating, improvements in the quality of family interactions were predominately attributed to the new parenting skills fathers were acquiring as part of the programme. They believed that these skills helped fathers to better identify and meet children's needs and fathers were frequently witnessed using these skills during the special family visits and on the telephones to improve their relationships with their children:

"Before, I thought I was a brilliant father [...] But these courses [...] you can maybe identify if things are wrong with them [children] more than I used to [...] you are able to communicate better with them and try to identify what's wrong. [...] It has given me a better bond with them [...] it has given me more confidence." (Participant 3 - Father) 


\section{The Role of Contact in Skill Acquisition}

Both fathers and staff agreed that it was essential that fathers had an opportunity to put into practice the parenting skills they were acquiring during the programme, if these skills were to become embedded:

"Theory is a great thing [...] we all need to do theory, but you know there is nothing like a bit of practical." (Participant 12 - Father)

Staff explained that when designing the Families Matter programme, they had deliberately sought to increase the quality and quantity of family contact available so as to improve family relationships and allow fathers to practice their newly acquired parenting skills. Fathers were actively encouraged by staff to use their new skills during telephone conservations and visits with their children. As part of the programme, staff delivering the parenting classes were also present during the special family visits to support fathers as they used these new skills in their interactions with their children. Staff were witnessed monitoring and supporting fathers as they attempted to put these skills into practice. In this way, staff were able to observe father-child relationships, assist when required and provide personalised feedback on fathers' use of these skills:

"They put it [newly acquired parenting skills] into practice on the [family] visits and [...] we will be looking out to make sure [...] that they are getting down to their child's eye level to speak to them. Down on the floor and playing with them." (Participant 30 - Staff) "Everybody is doing this course obviously to learn and to put in practice what they have learned through the classes at that family visit." (Participant 3 - Father)

Fathers explained that having the opportunity to rehearse new parenting skills was facilitating their acquisition and consolidation of these skills. Using these skills also built up their confidence in their parenting abilities and gave them additional tools to use to improve their relationships with their children: 
"I've learned a good wee bit from it [Families Matter programme] [...] how to discipline them [children] and [...] I've been trying it out at the [family] visits and it has been working. [...] My wee lad started to mess about and [I] got on the floor [...] got down to his level and said "[name] get up on my knee now". And he done it like that there. And [...] his ma was sitting telling him to get up and he wouldn't do it. [...] I was actually a wee bit shocked [that it worked]!" (Participant 10 - Father)

"You know what teenagers are like. When you phone them they say hello and it's hard to get conversation out of them. But you learn things in them [parenting] classes to say to your kids to get a conversation out of them. [...] That helps." (Participant 7 - Father)

Family members reported noticing fathers using their newly acquired parenting skills in their interactions with their children and were impressed with the effect this was having on their family relationships. In particular, accounts of fathers speaking to their children for longer periods of times and more often on the telephone were frequently heard, as well as fathers being able to interact better with their children:

"The best thing about the four hour [family] visit, whatever [father] had learned in the Families Matter programme, he was able to put it into practice [...] which was really exciting for him and for her [daughter]. [...] It was really good because it let me see that I could trust [father] with [daughter] [...] I knew he would be OK, he would be able to cope" (Participant 42 - Family member)

"She [partner] has noticed a change in me [father]. [...] Like I would ask more about the kids. I would ask him [child] on the phone, I would talk more and ask what was he doing at school, how was he getting on, what have you done, have you been good? You know things like that." (Participant 10 - Father)

Many fathers believed that they would be able to continue to use these newly acquired parenting skills on their release from prison, as they felt the opportunities available to rehearse these skills during the programme had been sufficient to fully internalise and assimilate them: 
"At the end of the day, I am learning stuff which I never knew I could have done before, that I'll be able to practice outside [...] with my kids, emotions and self-esteem and stuff." (Participant 3 - Father)

Only one father was more cautious in this respect, arguing that while the opportunities for increased contact during the programme had been very beneficial, as fathers continued to be imprisoned, they would remain limited in their ability to fully internalise these skills until they returned home to their families and were using these skills on a more frequent basis:

"I [have] learned from the parenting class [...] passive, assertive and aggressive [parenting styles], and stuff like that. There was a couple of other things too [...] but you are in jail. [...] You need to be in a home environment to put anything into practice that you learn." (Participant 15 - Father)

Unless, fathers were being released immediately on completion of the Families Matter programme, both fathers on remand and sentenced were worried about how the improvements in their father-child relationships would be maintained beyond the completion of the programme. As families could only avail of the additional telephone contact and family visits during the Families Matter programme, fathers and their families were concerned about how a return to preprogramme levels of contact would affect their father-child relationships:

"It is good for the child but it is bad at the end [of the programme] because [...] now he [child] is asking [...] "Is it the normal one [visit] or is it the family one [visit]?" Because if it is not that [family visit] one, he doesn't want to go." (Participant 41 - Family member) "You have a child where [...] [on the family visits] you can run over and grab her [...] play, do the things that mothers and fathers should be doing. [...] And then the next thing is [...] [you go back to the normal visits and] Daddy can't move. [...] Daddy's not allowed off this pink chair. [...] The child doesn't see the bigger picture, they think that their Daddy doesn't care about them anymore. Their Daddy doesn't want them [...] so you can actually give a child a complex." (Participant 12 - Father) 
Given the restrictions on movement and physical contact fathers experienced during the normal prison visits, as well as the uncertainties over telephone access prior to their participation in the Families Matter programme, it seemed that fathers were going to struggle to use their new parenting skills once the programme ended. As improvements in father-child relationships were generally attributed to fathers' use of these parenting skills, it seemed very likely that these improvements would be undone, if regular, quality contact in which fathers could use and rehearse their parenting skills was not provided beyond the completion of the programme. Accordingly, the lack of a plan for how to sustain and progress the benefits obtained from participating in the Families Matter programme beyond its completion until the fathers release from prison may undermine its potential long-term effectiveness.

\section{Discussion}

Based on these findings, families responded very positively to the increased contact available as part of the Families Matter programme. The additional telephone access and provision of special family visits was attributed with not only increasing the amount of contact between fathers and their children but also the quality of this contact, providing more opportunities for deep and meaningful father-child interactions to occur than were ordinarily available within the prison. Fathers were also provided with opportunities to put their newly acquired parenting skills into practice, allowing fathers to master the application of these skills and use these skills to improve their relationships with their children. These findings, therefore, indicate that prison based parenting programmes should ensure that opportunities to engage in deep and meaningful interactions with children and to use the parenting skills being taught are provided, if relationships between imprisoned parents and their children are to be improved.

The extent to which prison based parenting programmes may need to provide additional opportunities for contact to facilitate this type of parent-child interaction will vary depending on the 
opportunities for contact routinely available within a prison, the experience of families accessing these opportunities and the length of the father's imprisonment. Policies, practices and procedures surrounding prison visitation, telephone usage and letter writing vary substantially between different jurisdictions and even within different prisons within the same jurisdiction (Besemer et al., 2011; Hutton, 2016; Murray et al., 2007; Sharratt, 2014). As a result, the quantity and quality of father-child contact will differ from prison to prison, depending on the regime in that prison and its security status, influencing the opportunities fathers have to rehearse their parenting skills and use these skills to improve father-child relationships. Consequently, when establishing a prison based parenting programme, careful consideration should be given to the existing opportunities for family contact to assess if these opportunities are sufficient for mastering the parenting skills being taught on the programme, facilitate quality father-child interactions and cope with the length of time fathers are imprisoned for.

Within Maghaberry prison, fathers and family members' experiences of family contact prior to the Families Matter programme highlighted the importance of providing additional opportunities for increased contact to facilitate parenting skill acquisition and improvements in father-child relationships. As Maghaberry Prison is a high security adult male prison, it is unsurprising that it may adopt stricter, more security focused protocols surrounding family contact than may be present in other prisons. The continuing detention of political prisoners within Maghaberry Prison also amplified this focus on security (CJINI, 2015). For this reason, the additional opportunities for family engagement provided on the Families Matter programme were key to its success, as the opportunities for family contact ordinarily available within the prison limited the acquisition of the parenting skills being taught on the programme or the use of these skills in father-child interactions. This additional family contact, therefore, helped prevent a deterioration in family relationships, facilitated the acquisition of parenting skills and provided fathers with an opportunity to use these skills to improve their father-child relationships. 
Of course, the provision of such additional opportunities for contact may not be as necessary in prisons which already adopt longer, less restrictive, child friendly visiting practices. For example, in Sweden, it has been argued that the more frequent use of private family visits, open prisons, home leave, telephone and written communications have protected children from some of the negative effects of parental imprisonment (Murray et al., 2007). Similarly, in the Netherlands, more humane prison conditions and a tendency to provide more opportunities for family contact has been credited with helping to reduce some of the negative effects of parental imprisonment (Besemer et al., 2011). For this reason, whether a prison based parenting programme will benefit from including additional opportunities for family contact, will depend on the quality and quantity of family contact ordinarily available within that prison.

Yet, even if additional opportunities for family contact are provided, the extent to which improvements to father-child relationships are maintained and parenting skills retained in the longer-term is questionable, if there is a lack of a strategic vision for how this work will be progressed if fathers continue to be imprisoned beyond the completion of the programme. Similar to previous research, the findings indicate that prison visits which impose restrictions on movement and contact can limit the extent to which fathers can engage in deep and meaningful interactions with children and improve strained father-child relationships (Dennison et al., 2017; Hutton, 2016; Sharratt, 2014). According to Sharratt (2014), the quality of parent-child relationships prior to imprisonment can significantly affect children's motivation to maintain contact with their imprisoned parent. For those with positive relationships, children are believed to be motivated to maintain contact, despite the stresses and challenges they may encounter while doing so (Sharratt, 2014). Nevertheless, these children require regular contact if their wellbeing and positive fatherchild relationships are to be sustained (Sharratt, 2014). The additional telephone access and extra family visits available on the Families Matter programme played an important part in facilitating regular deep and meaningful contact between such children and their fathers. In contrast, for those with strained relationships, children are believed to be less willing to maintain contact and it is 
hypothesised that being exposed to stress or challenges may further decrease their motivation to maintain contact, potentially leading to relationship breakdown (Sharratt, 2014). Sharratt (2014) argues that under the right conditions such relationships can be improved. The findings from this research suggest that enhancing the fathers' parenting skills and allowing them to use these skills in the context of the less stressful and restrictive family friendly visits helped fathers to rebuild strained father-child relationships. However, a return to pre-programme levels of contact could threaten these newly rebuilt relationships, as children and fathers revert back to contact conditions which restricted meaningful interactions. In such circumstances, improvements to father-child relations may be undone and relationships may again begin to deteriorate.

Moreover, returning to pre-programme levels of contact would inhibit the ability of fathers to rehearse and use the parenting skills they had acquired. When teaching new parenting skills, skill maintenance is a key component of skill acquisition (Lindhiem, Higa, \& Trentacosta, 2014). Fathers need to be able to continue to use their parenting skills throughout the remainder of their imprisonment if they are to retain these skills. Returning to pre-programme levels of contact was going to immediately inhibit the ability of fathers to use some of these skills due to the prison's policy of restricting movement and physical contact during normal prison visitation. One possible solution was to only allow those nearly the end of their imprisonment to complete the programme but, by this time, family relationships may have broken down beyond repair. For this reason, fathers at any stage of their imprisonment were eligible to participate in the Families Matter programme but this meant there was a need to ensure that fathers remained able to practice their skills and maintain their family relationship during the remainder of their imprisonment until their release. Families Matter programme staff were aware of this issue and were seeking to remedy it but were restricted in their ability to do so without wider changes in the prison policies, procedures and practices surrounding family contact. Accordingly, despite the prison investing in a programme designed to improve parenting skills and family relationships, the potential long-term effectiveness 
of the programme was limited by the lack of a clear vision for how this work should be progressed and the prison's own policies, practices and procedures surrounding family contact.

There are, however, a number of limitations which must be borne in mind when interpreting the findings of this research. In particular, its sample size and focus on one parenting programme restricts the generalisability of its findings. Further, the lack of a follow-up limits the ability of the study to assess how a return to pre-programme levels of contact affected parenting skill retention or father-child relationships in the long-term. Future research should seek to overcome these limitations as well as identify how variations in prison policies, procedures and practices may affect the long-term effectiveness of prison based parenting programmes.

Nevertheless, despite these limitations, this research offers a number of insights into how prisons can enhance family contact and strengthen prison based parenting programmes to improve outcomes for children. Firstly, prison based parenting programmes should ensure that imprisoned parents have an opportunity to rehearse the skills they are acquiring, if they are to master the performance of these skills, use these skills to improve father-child relationships and minimise the negative impact of parental imprisonment on children. If suitable opportunities for family contact are not regularly available within a prison, the provision of such opportunities will be important for the potential success of prison based parenting programmes and their ability to improve child outcomes and family relationships.

Secondly, there needs to be clear plans for how the gains made as a result of participation in prison based parenting programmes will be maintained beyond programme completion until release, with different plans in place to cope with long term and short term imprisonment. If opportunities to maintain family contact and rehearse parenting skills are restricted upon programme completion, father-child relationships may begin to deteriorate and newly acquired parenting skills may be lost. This is particularly an issue in prisons whereby policies, practices and procedures surrounding visitation, telephone access and letter-writing may be more restrictive and not conducive to quality father-child interactions. In such situations, these policies, practices and 
procedures may ultimately undermine efforts to strengthen family relationships and weaken the long-term effectiveness of such programmes. Undermining family relationships can not only result in adverse outcomes for children but also hinder attempts to reduce re-offending, reintegration and desistance for fathers on their release from prison (Brunton-Smith \& McCarthy, 2016; Duwe \& Clark, 2013; Mears, Cochran, Siennick, \& Bales, 2012; Samposn \& Laub, 1993; Visher \& Travis, 2003).

Thirdly, depending on the prison, it may be necessary to review the policies, practice and procedures surrounding normal prison visitation so that security concerns can be better balanced with the needs of children. In particular, this research highlighted parents' worries about the potential for children to witness aggressive incidents during normal visitation by both those participating in visits and prison staff. Some steps that can be taken to address these concerns include moving towards a model of visitation which facilitates private visits, greater use of home leave, more child-friendly family visiting arrangements, the provision of family visiting slots (in which individuals are carefully chosen because of their reduced likelihood of engaging in conflict) and providing additional staff training on how to respond to conflict situations in the presence of children. The research also suggests that the suitability of normal prison visitation for those with autism and/or other development disorders may need to be reviewed to ensure that these children are not being disadvantaged, due to the failure of the prison to consider their particular needs.

Lastly, prison policies regarding telephone access may need to be revised so that regular contact between parents and their children can be maintained during imprisonment. In particular, sufficient telephones should be available to meet the needs of those imprisoned, imprisoned parents should have access to telephones at times convenient to families so children can speak to their imprisoned parent and making a telephone call should not be so costly that it hinders rather than facilitates frequent contact.

Accordingly, while prison based parenting programmes can improve parenting skills and father-child relationships, their potential long-term effectiveness may be restricted by prison policies, practices and procedures which inhibit the maintenance of these gains throughout the 
remainder of the parent's imprisonment. A failure to consider this issue, may result in parenting skills being lost and improvements in father-child relationships being undone, contributing to relationship breakdown and adverse outcomes for children. In developing justice policies, policymakers should, therefore, pay more attention to how prison policies, practices and procedures may have unintended knock on consequences for the wellbeing of children and their outcomes, as well as reducing offending.

\section{References}

Andrews, D., \& Dowden, C. (2005). Managing correctional treatment for reduced recidivism: A metaanalytic review of programme integrity. Legal and Criminological Psychology, 10, 173-187. doi:10.1348/135532505X36723

Barnardo's. (2015). The evaluation of the community support for offenders' families service. (). Ilford: Barnardo's.

Barr, R., Brito, N., Zocca, J., Reina, S., Rodriguez, J., \& Shauffer, C. (2011). The baby elmo program: Improving teen father-child interactions within juvenile justice facilities. Children and Youth Services Review, 33(9), 1555-1562. doi:10.1016/j.childyouth.2011.03.020

Barr, R., Morin, M., Brito, N., Richeda, B., Rodriguez, J., \& Shauffer, C. (2014). Delivering services to incarcerated teen fathers: A pilot intervention to increase the quality of father-infant interactions during visitation. Psychological Services, 11(1), 10-21. doi:10.1037/a0034877

Besemer, S., van der Geest, V., Murray, J., Bijleveld, C. C. J. H., \& Farrington, D. P. (2011). The relationship between parental imprisonment and offspring offending in England and the netherlands. British Journal of Criminology, 51(2), 413-437. doi:10.1093/bjc/azq072 
Boswell, G., Poland, F., \& Price, A. (2010). Prison based family support: An evaluation of the effectiveness $f$ the family support worker role piloted in four English prisons during 2009-10. (). London: Ministry of Justice National Offender Management Service.

Braun, V., \& Clarke, V. (2006). Using thematic analysis in psychology. Qualitative Research in Psychology, 3(2), 77-101.

Bronte-Tinkew, J., Carrano, J., Allen, T., Bowie, L., Mbawa, K., \& Matthews, G. (2008). Elements of promising practice for fatherhood programs: Evidence-based research findings on programs for fathers. Gaithersburg: U.S. Department of Health and Human Services Office of Family Assistance.

Brunton-Smith, I., \& McCarthy, D. J. (2016). The effects of prisoner attachment to family on re-entry outcomes: A longitudinal assessment. British Journal of Criminology, doi:10.1093/bjc/azv129

Bryman, A. (2008). Social research methods. Oxford: Oxford University Press.

Buston, K., Parkes, A., Thomson, H., Wight, D., \& Fenton, C. (2012). Parenting interventions for male young offenders: A review of the evidence on what works. Journal of Adolescence, 35(3), 731742. doi:10.1016/j.adolescence.2011.10.007

Butler, M. (2016) Prisoners and prison life. In D. Healy, C. Hamilton, Y. Daly \& M. Butler (ed.) The Routledge Handbook of Irish Criminology (pp337-355). Oxford: Taylor \& Francis.

Butler, M., Hayes, D., Devaney, J. \& Percy, A. (2015) Strengthening Family Relations: Review of the Families Matter Programme at Maghaberry Prison. Belfast: Barnardo's NI.

Criminal Justice Inspection Northern Ireland. (2015). Report of an unannounced inspection of Maghaberry prison 11-12 may 2015. Belfast: Criminal Justice Inspection Northern Ireland. 
Dennison, S., Smallbone, H., \& Occhipinti, S. (2017). Understanding how incarceration challenges proximal processes in father-child relationships: Perspectives of imprisoned fathers. Journal of Development Life Course Criminology, 3(1), 15-38.

Duwe, G., \& Clark, V. (2013). Blessed be the social tie that binds. Criminal Justice Policy Review, 24(3), 271-296. doi:10.1177/0887403411429724

Flynn, C., \& Eriksson, A. (2015). Children of prisoners. Annandale: The Federation Press.

Foster, H., \& Hagan, J. (2009). The mass incarceration of parents in America: Issues of race/ethnicity, collateral damage to children, and prisoner reentry. Annals of the American Academy of Political and Social Science, 623, 179-194. doi:10.1177/0002716208331123

Friedman, V. J., \& Antal, A. B. (2005). Negotiating reality: A theory of action approach to intercultural competence. Management Learning, 36(1), 69-86. doi:10.1177/1350507605049904

Garland, D. (1990). Punishment and modern society: A study in social theory. Oxford: Clarendon Press.

Hagan, J., \& Dinovitzer, R. (1999). Collateral consequences of imprisonment for children, communities, and prisoners. Crime and Justice, 26, 121-162. doi:10.1086/449296

Hagan, J., \& Foster, H. (2012). Intergenerational educational effects of mass imprisonment in America. Sociology of Education, 85(3), 259-286. doi:10.1177/0038040711431587

Hoffmann, H. C., Byrd, A. L., \& Kightlinger, A. M. (2010). Prison programs and services for incarcerated parents and their underage children: Results from a national survey of correctional facilities. Prison Journal, 90(4), 397-416. doi:10.1177/0032885510382087 
Hollin, C. (1995). The meaning and implications of programme integrity. In J. Maguire (Ed.), What works: Reducing reoffending - guidelines from research and practice (pp. 193-206). Chichester: Wiley.

Hutton, M. (2016). Visiting time. Probation Journal, 63(3), 347-361. doi:10.1177/0264550516663644

Kim, J. W., Ritter, F. E., \& Koubek, R. J. (2013). An integrated theory for improved skill acquisition and retention in the three stages of learning. Theoretical Issues in Ergonomics Science, 14(1), 22-37. doi:10.1080/1464536X.2011.573008

La Vigne, N. G., Naser, R. L., Brooks, L. E., \& Castro, J. L. (2005). Examining the effect of incarceration and in-prison family contact on prisoners'family relationships. Journal of Contemporary Criminal Justice, 21(4), 314-335. doi:10.1177/1043986205281727

Lindhiem, O., Higa, J., \& Trentacosta, C., J. (2014). Skill acquistion and utilization during evidencebased psychological treatments for childhood disruptive behavior problems: A review and meta-analysis. Clinical Child and Family Psychological Review, 17(1), 41-66.

Lipsey, M. W. (1995). What do we learn from 400 research studies on the effectiveness of treatment with juvenile delinquents. In J. Maguire (Ed.), What works: Reducing reoffending: Guidelines from research and practice (pp. 63-78). Chichester: Wiley.

Loper, A. B., \& Tuerk, E. H. (2006). Parenting programs for incarcerated parents: Current research and future directions. Criminal Justice Policy Review, 17(4), 407-427. doi:10.1177/0887403406292692

McCrudden, E., Braiden, J. H., McCormack, P., Sloan, P., \& Treacy, D. (2014). Stealing the smile from my child's face: A preliminary evaluation of the "being a dad" programme in a Northern Ireland prison. Child Care in Practice, 20(3), 301-312. 
Mears, D. P., Cochran, J. C., Siennick, S. E., \& Bales, W. D. (2012). Prison visitation and recidivism. Justice Quarterly, 29(6), 888-918. doi:10.1080/07418825.2011.583932

Meek, R. (2007). Parenting education for young fathers in prison. Child \& Family Social Work, 12(3), 239-247. doi:10.1111/j.1365-2206.2007.00456.x

Murray, J., Janson, C., \& Farrington, D. P. (2007). Crime in adult offspring of prisoners - A crossnational comparison of two longitudinal samples. Criminal Justice and Behavior, 34(1), 133-149. doi:10.1177/009385806289549

Murray, J., \& Murray, L. (2010). Parental incarceration, attachment and child psychopathology. Attachment \& Human Development, 12(4), 289-309. doi:10.1080/14751790903416889

Newman, C., Fowler, C., \& Cashin, A. (2011). The development of a parenting program for incarcerated mothers in Australia: A review of prison-based parenting programs. Contemporary Nurse, 39(1), 2-11.

Parson, T., Shils, E., \& Smelser, N. (2001). Toward a general theory of action: Theoretical foundations for the social sciences. New Jersey: Transaction Publishers.

Poehlmann, J., Dallaire, D. H., Loper, A. B., \& Shear, L. D. (2010). Children's contact with their incarcerated parents: Research findings and recommendations. American Psychologist, 65(6), 575-598.

Proctor, R. W., \& Dutta, A. (1995). Skill acquisition and human performance. Thousand Oaks: Sage.

Purvis, M. (2013). Paternal incarceration and parenting programs in prison: A review paper. Psychiatry Psychology and Law, 20(1), 9-28. doi:10.1080/13218719.2011.615822 
Samposn, R. J., \& Laub, J. H. (1993). Crime in the making: Pathways and turning points through life. London: Cambridge University Press.

Sharratt, K. (2014). Children's experiences of contact with imprisoned parents: A comparison between four European countries. European Journal of Criminology, 11(6), 760-775. doi:10.1177/1477370814525936

Stokes, J. O., Jent, J. F., Weinstein, A., Davis, E. M., Brown, T. M., Cruz, L., \& Wavering, H. (2016). Does practice make perfect? The relationship between self-reported treatment homework completion and parental skill acquisition and child behaviors. Behavior Therapy, 47(4), 538-549. doi:http://doi.org/10.1016/j.beth.2016.04.004

Visher, C., \& Travis, J. (2003). Transitions from prison to community: Understanding individual pathways. Annual Review of Sociology, 29, 89-113. doi:10.1146/annurev.soc.29.010202.095931

Wakefield, S., \& Wildeman, C. (2011). Mass imprisonment and racial disparities in childhood behavioral problems. Criminology \& Public Policy, 10(3), 793-+. doi:10.1111/j.17459133.2011.00740.x

Walmsley, R. (2016). World prison population list (11th edition). London: Institute for Criminal Policy Research.

Wildeman, C. (2009). Parental imprisonment, the prison boom, and the concentration of childhood disadvantage. Demography, 46(2), 265-280.

Wildeman, C. (2014). Parental incarceration, child homelessness, and the invisible consequences of mass imprisonment. Annals of the American Academy of Political and Social Science, 651(1), 7496. doi:10.1177/0002716213502921 